\title{
Los itinerarios del alma en La flauta mágica de Mozart. Hermenéutica de la iniciación.
}

\section{The Itineraries of the Soul in Mozart's Magic Flute. Hermeneutics of Initiation}

\author{
Blanca Solares \\ Centro Regional de Investigaciones Multidisciplinarias \\ Universidad Nacional Autónoma de México \\ bsolares@correo.crim.unam.mx
}

Resumen: $\quad$ La flauta mágica de Wolfgang Amadeus Mozart fue representada por vez primera en Viena en 1791. Es un lugar común asociar esta ópera con los misterios egipcios y la masonería, hacia la que Mozart mostraba simpatía, pero de la que se mantuvo a una afectuosa distancia. La flauta mágica es, más bien, un haz de enigmas, que incluso cuestionará los principios excesivamente masculinos de los francmasones. El presente ensayo, en un intento de mitoanálisis, hace énfasis en el mitologema de la iniciación, clave existencial de la aventura humana que echa sus raíces en el mito y que es recreada aquí mediante el lenguaje quintaesenciado de la música.

Palabras clave: Mozart, ópera, mito, símbolo, mitocrítica.

Abstract: $\quad$ Wolfgang Amadeus Mozart's Magic Flute was first performed in Vienna in 1791. It is common to associate this opera with Egyptian mysteries and the free masonry to which Mozart showed sympathy but maintained an affectionate distance from. The Magic Flute is, rather, a bundle of enigmas that call for the questioning of the excessively masculine principles of the free masons. This essay, in an attempt of mythanalysis, emphasizes the mythology of initiation, the existential key of human adventure that takes its roots in the myth and is recreated here through the quintessence language of music.

Keywords: $\quad$ Mozart, opera, myth, symbol, myth-critique.

Recibido: $\quad 15$ de octubre de 2018

Aceptado: 1 de marzo de 2019 


\section{Ineffabile mysterium}

La segunda mitad del siglo XVIII anuncia el ocaso de los regímenes monárquicos, el surgimiento de las revoluciones burguesas de fines de siglo, el cuestionamiento del papel de la Iglesia y el advenimiento de la Ilustración y el Romanticismo. Wolfgang Amadeus Mozart (27 de enero de 1756-1791) se ubica en la transición del ancien régime a la modernidad del siglo xIx. Desde pequeño, acostumbraba componer rápidamente sus obras a lo largo de sus frecuentes viajes de infancia, como por distracción. Decía que soñaba con partituras musicales. Poseía además una memoria musical extraordinaria. Una de las más conocidas anécdotas cuenta que una vez, después de haber escuchado a los cantores de la Capilla Sixtina interpretar el Miserere de Allegri - cuya partitura era exclusiva de la escolanía, por lo que estaba estrictamente prohibido que nadie la tuviese, y si alguien era sorprendido tomando notas se le expulsaba de manera inmediata-, Mozart, al llegar a su casa, la escribió de memoria, tan solo con haberla escuchado una vez.

Todavía en su época, la iglesia solía ser una ocasión para escuchar misa con música, acompañada de órgano y ejecutada por compositores de alta talla. La música religiosa no se diferenciaba radicalmente de la música de la corte. Tanto los príncipes como los prelados escuchaban lo mismo. Solo poco a poco los conciertos comenzaron a adquirir un carácter mundano y superficial. Pero aun en aquel entonces, Federico II, rey de Prusia, era considerado un flautista de talento. En general, en las cortes de la época, los soberanos solían tocar al menos un instrumento y tener conocimientos artísticos suficientes para apreciar el virtuosismo de un intérprete.

La música se tocaba en las cortes durante el almuerzo; lo mismo en la iglesia que en el palacio de algún príncipe. Los numerosos e ilustres comensales solían circular entre mesas y restos de comida mientras, en un rincón del salón, frente a un clavecín, bien podía estar sentado el mismo Mozart.

Los músicos, sin embargo, no se sentían humillados por tocar en estas condiciones. El padre de Mozart consideraba incluso que era un honor que sus hijos estuviesen invitados a tocar en esas reuniones en las que las personas no dejaban de parlotear, pasearse y comer. La música era considerada sobre todo "acompañamiento" o una especie de "fondo sonoro"; "música de amueblamiento", diría Eric Satie años después. En la época, nadie consideraba un sacrilegio escuchar música sin prestarle verdadera atención. Se oía tocar a célebres músicos a la vez que se hablaba y se iba pasando un plato de bocadillos. 
El Romanticismo, en el siglo XIX, por el contrario, exigiría un recogimiento casi religioso de parte del auditorio si se quería ser digno de escuchar la música que se interpretaba. Pero Mozart ya no viviría para contarlo. El problema de Mozart es que siempre estuvo a destiempo.

La flauta mágica de Mozart fue representada por vez primera en Viena, en 1791. Desde entonces, poseedora de una rara fuerza mitopoética, no ha dejado de cautivar universalmente a miles de escuchas y espectadores. La agraciada música de este incomparable compositor entra no solo por los oídos. Y, de hecho, en rigor, no se requeriría de palabras para hablar de ella. Sus melodías, tonos y ritmos tienen un don más allá del lenguaje hablado y nos transmiten o, mejor, revelan algo conceptualmente inarticulable, algo trascendente: un ineffabile mysterium. Más de 200 años después de haber sido compuesta, no es casual que esta obra se siga representando, porque aun en medio de la devastación y la violencia del orden social de nuestros días, sigue siendo capaz de verter un vívido mensaje de reconciliación, consuelo y esperanza. En el caso de Mozart, incluso, la música - la menos objetual de las artes - revela a través de su belleza, su fuerza y su transparencia melódica hasta qué punto es etérea la frontera entre música y religión, de religo, unión con lo trascendente. En ese sentido, decía Bernard Shaw que el quehacer mozartiano era "la única música hasta el momento compuesta, que no sonaría fuera de lugar en la boca de Dios" (Küng 2006: 43).

Ludwig van Beethoven utilizó uno de sus temas, el aria "Ein Mädchen oder Weibchen" cantada por Papageno, para realizar sus "Doce variaciones en fa mayor". Otra de sus arias, "Bein Männern, welche Liebe fühlen”, un dúo cantado por Papageno y Pamina, sirve de base también a Beethoven para componer otras siete recreaciones. Franz Liszt compuso un adagio, "Der welcher wandelt diese Strasse" (1881), inspirado en la misma obra.

En Francia, como en otros países, se siguen editando los principales temas de la ópera en adaptaciones especiales para niños. Y tampoco podemos obviar la deliciosa y magistral puesta en escena cinematográfica Trollflöjten, que Ingmar Bergman llevó a cabo en 1975.

El sabio egiptólogo Jan Assmann, autor de uno de los trabajos más completos sobre esta obra, coincide con Peter von Matt en que: junto con el Hamlet de Shakespeare y la Gioconda de Leonardo, La flauta mágica de Mozart puede considerarse como "el tercer gran enigma de nuestra cultura" (Assman 2006: 13). 


\section{Los itinerarios del alma}

El contenido de esta ópera, La flauta mágica, escrita en el último año de vida del compositor, paralelamente a un Requiem inconcluso, plantea diversas incógnitas en su análisis. Por una parte, su contenido suele relacionarse con la ritualidad egipcia; por otra, con la francmasonería, con la que Mozart simpatizó y a la que era afín. Dos de los libros de mayor influencia en el ámbito cultural esotérico y a la vez ilustrado frecuentado por Mozart eran: Mysterien der Aegyptier [Los misterios de los egipcios], del destacado mineralogista y egiptólogo Ignaz von Börn, jesuita de sólida formación clásica y conocimientos de lenguas antiguas; así como The Divine Legation of Moses [El legado divino de Moisés], publicado en tres volúmenes (1738-1741), de William Warburton, filólogo y obispo inglés, en el que se reactualizaban los escritos de Clemente de Alejandría sobre los misterios eleusinos.

Entre la llamada "francmasonería científica" de finales del siglo XVIII, la fascinación e investigación por los misterios de las tradiciones antiguas eran un tema de gran interés histórico y científico. No solo Börn y Warburton trabajaban en la recuperación de las tradiciones herméticas. Un número impresionante de verdaderas monografías sobre el tema aparecen a lo largo de esos años, entre ellas, estudios sobre la Cábala de los hebreos; los misterios de Mitra; la historia de la liga pitagórica, y los misterios fenicios, hindús, cabíricos, hebreos, eleusinos y báquicos. La crítica ilustrada a la Iglesia corría paralela al estudio, recuperación y apertura a las llamadas tradiciones paganas y a las raíces del hermetismo. ${ }^{1}$

El libreto de La flauta mágica fue escrito por Emmanuel Schikaneder (1791), personaje curioso y atrevido director de teatro de arrabal, en estrecha colaboración con Mozart, a quien supo respetar. ${ }^{2}$ Los dramati personae de esta historia son: Sarastro, el Gran Sacerdote; el Príncipe Tamino; la Princesa Pamina, hija de la Reina de la Noche; la Reina de la Noche, reina de las fuerzas del mal; Papageno, hombre pájaro; Papagena, mujer pájaro; Monostatos, servidor de Sarastro; todos los Sacerdotes, servidores de Sarastro y las Damas,

1 Entre las investigaciones más destacadas, además de las citadas están: Sobre los antiguos y nuevos misterios, del orientalista y teólogo Johan August (barón de Starck, 1741-1816). Así también, Los misterios hebreos o la francmasonería religiosa más antigua, de Karl Leonhardt Reinhold, filósofo jesuita y escritor, discípulo de Herder, en el que se sostiene la tesis del origen egipcio del monoteísmo (Assmann 2006: 132).

2 Dice él mismo que meditó la ópera "laboriosamente con el maestro" (Assmann 2006: 53). 
servidoras de la Reina de la Noche, al igual que los muchachos o Geniecillos benéficos.

Aunque pueden ser muchos los motivos de esta obra, en lo que sigue intento destacar solo el tema de la iniciación, uno de los aspectos centrales del universo mítico y ritual de las sociedades tradicionales.

La iniciación, me parece, es uno de los motivos centrales de la historia que Mozart nos quiere contar, marcando musicalmente cada uno de los momentos de la aventura del personaje mítico que articulan la obra: la desilusión del neófito (I); el enfrentamiento del iniciado con distintos peligros a través de los cuales deberá probar su autodominio (II); el de su victoria a través de la profunda transformación de su ser (III). Pues con la iniciación no se trataba solo de aprender (mathein) sino de sufrir (payhein), juego de palabras que, en griego, querían expresar la necesidad de experimentar una sacudida emocional o "impresión afectiva" por parte del iniciado. Esta estructura básica, si se puede decir así, de alguna manera expresaba la concepción ética, social y política de la francmasonería vienesa con relación a la política y a la religión. Pero el genio de Mozart expresó todos estos ideales en un lenguaje musical propio que, incluso, los supera.

\section{Tamino y la serpiente, la iniciación de Tamino}

EL ORADOR: ¿A dónde quieres ir? ¿Qué buscas en este santuario?

TAMINO: El reino del amor y la virtud.

EL ORADOR: Esas palabras son excelsas. ¿Pero cómo llegarás ahí?

No te guían ni el amor ni la virtud; solo te animan la muerte y la venganza. ${ }^{3}$

Si comparamos la sencilla narración de La flauta mágica con la estructura del "monomito" expuesta por el hermeneuta del pensamiento mítico Joseph Campbell en su libro El héroe de las mil caras (1997), tenemos una estructura paralela que sintéticamente está integrada por las siguientes fases de la aventura del héroe mitológico: la partida, la iniciación, el regreso y las llaves.

3 Los extractos del libreto La flauta mágica aquí citados pueden consultarse en <https://es.scribd.com/document/58490761>, consultado el 1o de noviembre de 2018. 
No es casual que la obra de Mozart guarde una estructura iniciática, ni que sea precisamente un Príncipe (o futuro monarca) el que en primera instancia deba ser iniciado para alcanzar su felicidad y el amor, estados individuales de los que socialmente depende su reino. Como todos los mortales, el Príncipe debía purificarse. Aprender a escapar de las redes del poder. Aprender a resguardar la armonía entre los hombres, y entre los hombres y los dioses. La función de la iniciación, en las culturas tradicionales, era revelar a cada nueva generación un mundo abierto a lo transhumano; ayudar a comprender que el amor no puede alcanzarse mientras en el corazón anide la venganza. Para C. G. Jung, la individuación es la meta de la auténtica vida humana, y se alcanza a través de una serie de pruebas de tipo iniciático a lo largo de la existencia. Estas fases de la aventura humana configuran, es decir, dan cuerpo, a la estructura mítica de La flauta mágica. Pero, a partir de aquí, Mozart y Schikaneder abandonan las teorías francmasonas, base de una sociedad de hombres, exclusivamente masculina. Los postulados de las investigaciones de Börn, así como las de Warburton, rigurosos y eruditos, son transformados en un lenguaje más allá de los ilustrados y de la corte; quieren contribuir en lo posible a una educación estética y puesta al alcance de todos los oídos.

\section{PAmina: (Ein) Weib, das Nacht und Tod nicht scheut}

[Una mujer que no teme ni a la noche ni a la muerte]

La flauta mágica, como venimos diciendo, guarda una relación estrecha con la estructura del monomito. Pero, en contraste con la mayoría de los mitos que conocemos - centrados en la aventura del héroe mitológico masculino-, Mozart resalta aquí la necesaria iniciación en el amor también de la mujer. De manera sorpresiva, introduce un giro que está más allá de la masonería y a la que incluso parece contradecir.

La tradición mítica de corte patriarcal no suele resaltar la iniciación femenina. La mayoría de los mitos están centrados en la aventura del héroe masculino. El papel de la mujer se relega al de hechicera, bruja, madrastra, o, posteriormente en el siglo XIX, femme fatal, sin que sepamos del proceso o las pruebas que la mujer también debe atravesar antes de descubrir su propia feminidad. Mozart, sin embargo, tiene aquí la audacia de introducir en su composición, tanto en el libreto como en la música, al eterno femenino (Goethe) como personaje dramático y central de la aventura humana. 
En un determinado momento, uno de los giros más audaces de la trama es el hecho de representar a este panteón de fuerzas sobrenaturales en torno de la Reina de la Noche que, en resonancia con Deméter, Isthar o Isis, sufre la pérdida de un ser amado al que lucha por recuperar. La Reina de la Noche es la diosa de la Luna y el Cielo estrellado que pare al Sol, según la mitología egipcia. Pero también un ser que en su corazón alberga odio y rencor hacia Sarastro, al que pretende destruir, incluso si para ello deba servirse de su propia hija. Dice La Reina nocturna a Pamina, entregándole un puñal:

\author{
¡Repudiada y abandonada serás \\ por toda la eternidad, \\ destruidos quedarán \\ todos los lazos de la Naturaleza, \\ si Sarastro no expira por tu mano!
}

La obra expone aquí a la vez que el lado protector y afectivo de la feminidad, su aspecto vengativo y terrible. El relato muestra al eterno femenino en su ambigüedad supraterrenal, tanto en su carácter amoroso como en el monstruoso. Está asociado con la belleza y el misterio, la noche y lo oculto, pero también con la mentira, la hechicería y la superstición. La Reina de la Noche acusa a Sarastro de secuestro; burla su autoridad; envía a sus damas a su templo con toda la intención de hacer que los héroes (Tamino y Papageno) rompan su voto de silencio; y ejerce chantaje sobre Pamina, aprovechando el acoso lascivo que Monostatos, sirviente de Sarastro, ejerce sobre la doncella. Madre primordial, la Reina de la Noche, estiliza y sublima las potencias naturales. Como dice Eugenio Trías, arrasa con su manto lunas y estrellas en remolino: "La música que le corresponde es arrebatadora, se impone nada más pronunciarse, se abre paso en medio de la maleza hasta alcanzar cimas soprano con las más audaces coloraturas. Pocas veces se ha conseguido plasmar de una vez para siempre, para toda la eternidad, en dos únicas arias, una presencia mítica tan arrolladora" (Trías 2010: 218).

Pero Pamina no es la princesa pasiva que espera dormida ser despertada por el beso de un príncipe; al contrario, aquí debe también ser sometida a difíciles pruebas antes de ganar su matrimonio. De manera que, tal pareciera que el mensaje dirigido a Tamino respecto de los peligros de la mujer (Cuidaos de las insidias femeninas / ¡es el primer deber de la alianza!), no vaya solo dirigido a él, sino también a la propia Pamina, que deberá descubrir 
(y posteriormente trascender; asumir y comprender) que el odio y el deseo de muerte y venganza de su madre son también atributos de la feminidad, de los que habrá de aprender a mantenerse alerta. Como dice también Trías, Pamina es sin duda el gran personaje de esta fabola in música (Trías 2010: 219), es hija de la Reina de la Noche, echa sus raíces al árbol del Mito. Pero, a diferencia de Pamino, el príncipe valiente de todos los cuentos infantiles, Pamina posee un carácter complejo o, dicho en términos musicales:

Como los instrumentos predilectos de Mozart, especialmente los clarinetes, tiene una extensa gama tonal y tímbrica, puede circular rápidamente por los bajos y elevarse hasta los cúmulos y altocúmulos tonales. Puede también deslizarse, de forma dolorida, sufriente, hacia el sol menor, volcando en un aria todo su dolor acumulado. Pero es capaz de sobreponerse de forma heroica y guiar a Tamino en el recorrido de las pruebas rituales (Trías 2010: 221).

\section{La sombría noche de la muerte}

La flauta mágica, podemos insistir junto a Jan Assmann, es pues un haz de enigmas: religiosos, políticos, psicológicos, que han dado y siguen dando pie a numerosas interpretaciones. No se reduce a la masonería ni tampoco a los misterios de Isis, a los que sin embargo se alude en distintos momentos de la obra. Guarda la estructura del mito en el sentido de que su narración no sigue una exposición lógica y causal; plantea preguntas para las cuales no tenemos una respuesta a priori: ¿es posible el amor?, ¿cuál es la naturaleza de lo femenino?, ¿qué sentido tienen las pruebas de la individuación?

Su propio tempo narrativo es como el del mito (G. Durand 2018), anula el tiempo, nos hace vivir una "miniatura de eternidad" (J. Hersch). A través de la música nos transporta al ilud tempus (M. Eliade) con el que comienzan todas las historias. No puede explicarse de una vez por todas; al contrario, está conformada de tal manera que es como una fuente o pozo del que siguen abrevando - hasta nuestros días - la literatura, el teatro, la pintura e incluso, en la era de la reproductibilidad técnica, el cine, el video y la misma música.

Quizá su principal mitologema (pregunta que el hombre se plantea y que carece de una respuesta precisa) es el misterio del amor. Simbólicamente, esta respuesta se articula como una aventura heroica o de construcción del 
ser humano como humano, sin excluir la confrontación con los más bajos instintos del hombre.

Por lo demás, sabemos que la flauta no era el instrumento preferido de Mozart; ¿qué subyace entonces a esta elección?

Orfeo gozaba del don excepcional del canto. Cuando Eurídice murió picada por un escorpión o una serpiente, se le permitió rescatarla del inframundo con la sola condición de que aunque ella lo implorara, él no se volvería a verla. Pero Orfeo dudó, y Eurídice fue remitida al submundo. Unos dicen que Orfeo fue destazado por las ménades; pero que su cabeza continuó cantando a través de los siglos. Tamino - por su parte — se enfrenta a las pruebas armado con una simple flauta, una elección a través de la cual, Mozart, ciertamente, pareciera querer restituir a la música, y solo a la música —más que al canto vinculado con la palabra-, su poder sagrado, divino o celestial.

Frente al predominio de la "música de acompañamiento", propio del estilo rococó de la segunda parte del siglo XVIII, como hemos señalado "música para amueblar", con La flauta mágica Mozart restituye a la música pura su carácter primordial y sobrenatural. Dice Pamina respecto de la flauta: "En una hora mágica la talló / mi padre de lo más hondo / de una encina milenaria, / entre rayos y truenos, tempestades y huracanes". 4

La flauta mágica es la auténtica protagonista de la obra, el símbolo que condensa el sentido de toda la narración. Pocas veces entra en acción, solo en los momentos de mayor importancia, cuando su tañedor se encuentra en peligro de muerte. La flauta, o la música, junto con la fuerza del amor, son los instrumentos con los que Tamino y Pamina logran superar la avasalladora violencia de las pruebas de fuego y agua del avasallador rito de pasaje que es la vida. En ese sentido, como dice Sören Kierkegaard a propósito de Mozart, esta obra despliega las potencias del "erotismo musical". ${ }^{5}$ Más allá de las intrigas, el engaño y la venganza, a través de la música y el amor, Tamino y Pamina se magnifican mutuamente. Pues, como también lo sabe Diotima, según Hölderlin-Hiperión, "el amor engendró el mundo" y, agregaría Mozart, consagrando con su armonía musical a todos los seres.

Mozart anuncia el Romanticismo del siglo XIX, o quizá mejor el hermetismo que, a decir de Gilbert Durand (2018), se infiltrará nuevamente en la cuenca semántica del siglo Xx. Pero que, a fines del siglo XVIII, todavía deberá

4 Cit. por Assmann 2006: 209

5 Véase, de este autor, Estudios estéticos I (Diapsálmata. El erotismo músical 1), Málaga, Ágora, 1996. 
atravesar la predominancia del mito prometeico y dionisiaco. Su interés en las religiones mistéricas, tanto egipcias como griegas, no fue casual ni ajeno a su peculiar fe católica. Ahora bien, fundamentalmente, Mozart era un creador. No eligió para su obra un título como Los misterios egipcios, sino otro que para él expresaba mejor lo que consideraba que eran los valores más altos: el amor y la música. El poder seductor y creativo del amor y la música que, como desarrollo armónico, nos proponen una aventura iniciática. Dice Pamina: "Por el poder de la música / avanzamos /Alegres por la sombría noche / de la muerte".

\section{Hermenéutica de la iniciación}

Si algo caracterizaba la transmisión tradicional de la cultura en las sociedades antiguas, era que toda adquisición de un saber o un poder con su doble cara, técnica y simbólica, traía implicado un proceso iniciático por parte de los miembros individuales de la comunidad, es decir, los aprendizajes vitales eran comprendidos y asumidos como auténticos passages que trasmutaban radicalmente la biografía del iniciado. Solo así este podía acceder a los códigos culturales y sobrenaturales con el fin de orientarse en el mundo.

Para el hombre premoderno o tradicional, los actos más relevantes de la vida habían acontecido en el tiempo mítico de los orígenes. La mayoría de los mortales solo podían tener acceso a ese saber, a esa "ciencia tradicional", si eran instruidos durante algún tiempo en ceremonias secretas, al final de las cuales, si se habían superado una serie de arduas pruebas, se podía ser merecedor del conocimiento sagrado. La vida religiosa del hombre se dividía en etapas acordes con el desarrollo no solo físico sino psíquico o espiritual. Los ritos de nacimiento, pubertad, matrimonio y, finalmente, de muerte marcaban decididamente la evolución del niño en adulto consciente y responsable. Esta serie de transiciones se consideraban también "crisis vitales", porque cuestionaban nuestro lugar en el mundo y daban relevancia a las encrucijadas que marcaban definitivamente nuestra vida.

Según Mircea Eliade un símbolo tiene una historia. Con toda probabilidad los rituales de iniciación estaban presentes desde el Paleolítico y encontraron su auge entre los órficos y los misterios eleusinos. Muchas veces su simbolismo se degrada. Pero otras, como es el caso del simbolismo y la mitología de La flauta mágica, se expresa admirablemente enriquecido. Así, como dice 
Hans Werner Henze, en los acordes de La flauta mágica, Mozart sube a las alturas "como un yo transfigurado en cuerpo y alma". ${ }^{6}$

A través de los tiempos, admirablemente, Mozart ha logrado apelar de manera notoria a nuestra sensibilidad artístico-musical y mítico-poética. Su música espiritual se caracteriza por una "gozosa hondura desde arriba", dice el teólogo protestante Karl Barth, especialmente aficionado a las misas de Mozart. Asimismo, agrega: "lo genuinamente conmovedor y calmante de su música es que perceptiblemente desciende de unas alturas desde las cuales se observa, tanto el lado derecho como el lado izquierdo de la existencia, el gozo y el dolor, la vida y la muerte en su realidad, pero asimismo en la posibilidad de su trascendencia” (Küng 2006: 29).

\section{Bibliografía}

Assmann, Jan (2005). Die Zauberflötte. Oper und Mysterium, Carl Hanser Verlag. Existe versión en español: El secreto de la Flauta Mágica. Ópera y misterio, Madrid, Akal, 2006.

CAMPBELL, Joseph (1997). El héroe de las mil caras, $5^{\mathrm{a}}$. reimpr., México, FCE.

Durand, Gilbert (2018). "De Constanza a Pamina", en Blanca Solares, Gilbert Durand: Escritos musicales. La estructura musical de lo imaginario, Barcelona, Anthropos: 24-45.

KirKegAARD, Sören (1996), Estudios estéticos I (Diapsálmata. El erotismo músical 1), Málaga, Ágora.

KüNG, Hans (2006). Música y religión. Mozart, Wagner y Bruckner, Madrid, Trotta.

TRíAs, Eugenio (2010). "Wofgang Amadeus Mozart: veo la muerte acercarse", en La imaginación sonora. Argumentos musicales, Barcelona, Galaxia Gutemberg: 197232.

SCHIKANEDER, Emanuel (1791). La flauta mágica. Libreto, en <https://es.scribd.com/ document $/ 58490761>$, consultado el 26 de febrero de 2019. Para una edición crítica de la partitura, consultar: $<$ http://nma.at $>$.

\section{Discografía}

MozArt, Wolfgang Amadeus (2010). La flauta mágica, Orquesta Filarmónica de Berlín dirigida por Herbert von Karajan. Ediciones La Societé du Fígaro, Paris.

Liszt, Franz. "Der welcher wandelt diese Strasse", Adagio von Die Zauberflöte von W. A. Mozart, S.634a, for piano four-hands, <https://www.youtube.com/ watch?v=Ft5 $\mathrm{XX} 8 \mathrm{yeWoY}>$, consultado el 1 de octubre de 2018.

6 Citado por H. Küng (2006: 29). 
Beetohven, Ludwig Van. Doce variaciones en fa mayor, op. 66 para violonchelo y piano, <https://www.youtube.com/watch?v=VEqCC19bDgQ>, consultado el 1 de octubre de 2018.

BeEtohVen, Ludwig Van. Siete variaciones en mi bemol mayor para violonchelo y piano, op. 46, <https://www.youtube.com/watch?v=uyt6IqrM2DI>, consultado el 1 de octubre de 2018.

\section{Blanca Solares}

Investigadora del Programa en Estudios de lo Imaginario, del Centro Regional de Investigaciones Multidisciplinarias de la UnAM, Campus Morelos, y coordinadora del Proyecto "Hermenéutica e historia del mito (Imagen, símbolo, arte y religión)”, adscrito a la Red Internacional de Centros de Investigación de lo Imaginario. Entre sus trabajos cabe destacar: Madre Terrible. La Diosa en la religión del México antiguo (2007), Uixtocíhuatl o el simbolismo sagrado de la Sal (2012), Imaginarios Musicales. Mito y Música (edición), 2 vols. (2016) y, de reciente aparición, Gilbert Durand, escritos musicales. La estructura musical de lo imaginario (2018). 